\title{
Pseudonocardia chloroethenivorans sp. nov., a chloroethene-degrading actinomycete
}

\author{
Seung-Bong Lee, ${ }^{1}$ Stuart E. Strand, ${ }^{2}$ H. David Stensel ${ }^{1}$ \\ and Russell P. Herwig ${ }^{3}$ \\ ${ }^{1}$ Department of Civil and Environmental Engineering, Box 352700, University of Washington, \\ Seattle, WA 98105-2700, USA \\ ${ }^{2}$ College of Forest Resources, Box 352100, University of Washington, Seattle, \\ WA 98105-2100, USA
}

Correspondence

Russell P. Herwig

herwig@u.washington.edu
${ }^{3}$ School of Aquatic and Fishery Sciences, Box 355020, University of Washington, Seattle, WA 98195-5020, USA

\begin{abstract}
A bacterial strain, $\mathrm{SL}-1^{\top}$, capable of degrading trichloroethene was isolated from a laboratory enrichment in the Department of Civil and Environmental Engineering, University of Washington, USA. The material in the enrichments was derived from a soil sample from Seattle, WA, USA. Strain $\mathrm{SL}-1^{\top}$ was capable of using phenol as a source of carbon and energy. Chemotaxonomic, morphological, physiological and phylogenetic analyses showed that strain $\mathrm{SL}-1^{\top}$ is a member of the genus $P$ seudonocardia. The ability of strain $\mathrm{SL}-1^{\top}$ to utilize phenol and degrade trichloroethene, as well as other phenotypic properties and the results from a 16S rRNA phylogenetic analysis, led to the proposal of a novel species, Pseudonocardia chloroethenivorans sp. nov. The type strain is SL-1 ${ }^{\top}$ (=ATCC BAA-742 ${ }^{\top}=$ DSM 44698 $\left.{ }^{\top}\right)$. Trichloroethene and other chloroethenes are major pollutants at many environmental sites, and $P$. chloroethenivorans has biodegradation properties that should be of interest to environmental microbiologists and engineers.
\end{abstract}

Trichloroethene (TCE) and other chloroethenes such as perchloroethene, cis-1,2-dichloroethene (cis-DCE) and chloroethene (also known as vinyl chloride, VC) are compounds that are widely distributed at many contaminated environmental sites around the world. In the US, TCE is recognized as the most commonly found contaminant at Superfund sites (US Environmental Protection Agency, 1991). These compounds are known as, or suspected of being, human carcinogens, and are regulated. The bioremediation and biodegradation of TCE has been examined by many microbiologists and environmental engineers for over 15 years. Anaerobic and aerobic transformation pathways and micro-organisms have been described (Fetzner, 1998; Gerritse et al., 1995). In field and laboratory experiments, many investigators have used phenol, toluene and methane as growth substrates and as inducers for enzymes that are capable of degrading chlorinated ethenes (Nelson et al., 1987, 1988; Sullivan et al., 1998). The fortuitous degradation of toxic compounds is known as co-metabolism (Semprini, 1995).

Published online ahead of print on 4 July 2003 as DOI 10.1099/ ijs.0.02488-0.

Abbreviations: cis-DCE, cis-1,2-dichloroethene; RDP-II, Ribosomal Database Project II; TCE, trichloroethene; VC, vinyl chloride.

The GenBank accession number for the 16S rRNA gene sequence of Pseudonocardia chloroethenivorans SL-1 ${ }^{\top}$ is AF454510.
In previous studies, several different species of aerobic bacteria that are capable of degrading TCE were enriched and isolated by using phenol or other aromatic compounds (Ensley, 1991). Several species and strains were members of the class Proteobacteria and species of the genus Pseudomonas. There are also reports of Gram-positive bacteria that are capable of degrading TCE, when grown on phenol. We report on the enrichment and isolation of an actinomycete, strain SL-1 ${ }^{\mathrm{T}}$, which is capable of growing on phenol and degrading TCE, cis-DCE and VC. On the basis of chemotaxonomic, physiological and phylogenetic properties, the strain was characterized as a newly described species of the genus Pseudonocardia.

Strain SL- $1^{\mathrm{T}}$ was isolated from an enrichment that was developed and maintained in the Department of Civil and Environmental Engineering at the University of Washington. Details of the enrichment have been described previously (Lee et al., 2000). To summarize, the enrichment was contained in a laboratory-scale, shallow, sparged, suspended growth bioreactor. TCE-contaminated air was bubbled continuously into the 21 cylinder. Phenol was used as the primary carbon and energy source. Phenol was introduced every $2 \mathrm{~h}$ to maintain a 6 day retention time for solids. The reactor was inoculated with a TCE-degrading mixed aerobic culture that had been used in a previous investigation (Bielefeldt et al., 1995). A microbial enrichment that was 
capable of degrading phenol and TCE developed in 1 month. Observations of the reactor contents using a phase-contrast microscope suggested that the enrichment consisted largely of a branching filamentous type of microorganism. The enrichment was maintained for several months.

Pure cultures of a bacterium were isolated from the enrichment culture by performing a serial dilution of the enrichment and streaking aliquots onto mineral-medium agar plates containing $14 \mathrm{mg}$ phenol $\mathrm{l}^{-1}$. The mineral medium consisted of the following $\left(\mathrm{l}^{-1}\right): 700 \mathrm{mg} \mathrm{K \textrm {K } _ { 2 }} \mathrm{PO}_{4}$, $1000 \mathrm{mg} \mathrm{K}_{2} \mathrm{HPO}_{4}, 200 \mathrm{mg} \mathrm{NH}_{4} \mathrm{Cl}, 30 \mathrm{mg} \mathrm{MgSO}$, $66 \cdot 5 \mathrm{mg}$ $\mathrm{CaCl}_{2} \cdot 2 \mathrm{H}_{2} \mathrm{O}, 300 \mathrm{mg} \mathrm{NaHCO}{ }_{3}, 55 \mu \mathrm{g} \mathrm{CuCl} 2 \cdot 2 \mathrm{H}_{2} \mathrm{O}, 150 \mu \mathrm{g}$ $\mathrm{ZnCl}_{2}, 20 \mu \mathrm{g} \mathrm{NiCl} 2.6 \mathrm{H}_{2} \mathrm{O}, 880 \mu \mathrm{g} \mathrm{FeSO}_{4} .7 \mathrm{H}_{2} \mathrm{O}, 135 \mu \mathrm{g}$ $\mathrm{Al}_{2}\left(\mathrm{SO}_{4}\right)_{3} \cdot 18 \mathrm{H}_{2} \mathrm{O}, 280 \mu \mathrm{g} \mathrm{MnCl} 2 \cdot 4 \mathrm{H}_{2} \mathrm{O}, 55 \mu \mathrm{g} \mathrm{CoCl} 2 \cdot 6 \mathrm{H}_{2} \mathrm{O}$, $30 \mu \mathrm{g} \mathrm{NaMoO} \cdot 2 \mathrm{H}_{2} \mathrm{O}$ and $50 \mu \mathrm{g} \mathrm{H}_{3} \mathrm{BO}_{3}$ (Lee et al., 2000). Colonies were restreaked on the mineral medium. All colonies had a similar morphology. A single colony was then transferred into a $160 \mathrm{ml}$ serum bottle containing $1 \%(\mathrm{w} / \mathrm{v})$ yeast extract. The yeast extract-grown culture was transferred onto an agar plate containing $14 \mathrm{mg}$ phenol $\mathrm{l}^{-1}$. Colonies growing on a phenol agar plate were selected. After three more transfers onto phenol agar plates, a pure culture was isolated. The pure culture, strain SL- $1^{\mathrm{T}}$, was maintained in a chemostat fed with $14 \mathrm{mg}$ phenol $\mathrm{l}^{-1}$ and operated at a 6 day retention time for solids. The mineral medium described above was used in the chemostat.

The concentrations of TCE, cis-DCE and VC were measured in the gas phase of the chemostat by using a GC equipped with a flame-ionization detector (Lee et al., 2000). Phenol concentrations in the liquid were monitored using a colorimetric method, the CHEMets phenols kit (CHEMetrics), and detected quantitatively by using an acetic anhydride derivatization method (Coutts et al., 1979).

The morphology of the enrichment and SL- $1^{\mathrm{T}}$ was examined periodically using phase-contrast light microscopy. Carbon utilization of a variety of substrates was examined using a GP2 MicroPlate (Biolog). To prepare material for the Biolog plate, mycelial fragments from the agar surface were transferred in $13.5 \mathrm{ml} 0 \cdot 2 \%$ carrageenan type II. The $\mathrm{OD}_{590}$ was adjusted to approximately $0 \cdot 2$. Following a 10 fold dilution with $0 \cdot 2 \%$ carrageenan type II, the bacterial solution was inoculated into a GP2 MicroPlate with $100 \mu \mathrm{l}$ per well. Turbidity within individual wells was determined after incubating the plate for 5 days at $25^{\circ} \mathrm{C}$.

Standard phenotypic tests used previously for describing novel species of Pseudonocardia and other actinomycetes were also performed (Gordon et al., 1974). Inoculated media for these tests were incubated at $28^{\circ} \mathrm{C}$ for a period of up to 28 days. The production of acid from a variety of carbohydrates was examined using a basal inorganic nitrogen medium. The $\mathrm{pH}$ of this medium was adjusted to $\mathrm{pH} 7 \cdot 0$ before the addition of the bromocresol purple solution; $0.5 \mathrm{ml} 10 \%$ carbohydrate solution was added to $4.5 \mathrm{ml}$ basal inorganic nitrogen medium. The decomposition of adenine, hypoxanthine, L-tyrosine and xanthine was observed by adding these compounds separately to nutrient agar and examining the plates for zones of clearing around the colonies. Tolerance of additional $\mathrm{NaCl}$ (Reichert et al., 1998) was examined by adding 3, 4 and $5 \%(\mathrm{w} / \mathrm{v}) \mathrm{NaCl}$ to peptone/yeast extract agar (Evtushenko et al., 1989). Decomposition of urea was determined using urease broth (Gordon et al., 1974).

The diaminopimelic acid, cell-wall sugar and menaquinone composition of strain SL-1 ${ }^{\mathrm{T}}$ was determined by the Probionic Company (Yusong, Korea) using standard procedures. The isomer type of the diaminopimelic acid in the cell wall was identified by TLC according to Komagata \& Suzuki (1987). The sugars of the cell wall were analysed as described previously (Saddler et al., 1991). Menaquinones were analysed using reverse-phase HPLC as described by Komagata \& Suzuki (1987).

Whole-cell fatty acid methyl esters were determined by following the protocols described by MIDI (1993) with the exception of the medium that is routinely suggested by MIDI for aerobic heterotrophic bacteria; BBL trypticase soy broth (TSB) agar (BD Diagnostic Systems) was not satisfactory for growing a sufficient amount of strain SL- $1^{\mathrm{T}}$ biomass. Preliminary experiments were performed with other solid media used previously for the cultivation of actinomycetes, including malt agar and actinomycete medium, but none provided sufficient mass for performing the MIDI fatty acid analysis. The protocol suggested by MIDI for the cultivation of actinomycetes was followed: this recommended inoculating BBL TSB in $125 \mathrm{ml}$ flasks and shaking the flasks at 125 r.p.m. at $28^{\circ} \mathrm{C}$. Cells were grown for 7 days and harvested by decanting the supernatant.

For the extraction of DNA to be used for sequencing of the $16 \mathrm{~S}$ rDNA, strain SL- $1^{\mathrm{T}}$ was grown in TSB at $28^{\circ} \mathrm{C}$. Four small aggregates of cells, removed from the broth using a pipette tip, were used for DNA preparation according to the protocol described by Bio-Rad for the InstaGene matrix; $10 \mu \mathrm{l}$ from the resulting supernatant was used in a $100 \mu \mathrm{l}$ PCR. The $16 \mathrm{~S}$ rDNA was selectively amplified from genomic DNA with a PCR using the universal bacterial primer $8 \mathrm{fb}$-JP (5'-GAGGCGCGCCGAGTTTGATCCTGGCTCAG- $3^{\prime}$ ) as the forward primer and universal primer 1492RU-JP (5' -TTTTAATTAAGGCCTTGTTACGACTT-3') as the reverse primer. These amplification primers have restriction sites at the $5^{\prime}$ ends for $A s c \mathrm{I}(8 \mathrm{FB}-\mathrm{JP})$ and $\mathrm{PacI}$ (1492RU-JP). The PCR cocktail included $10 \mu \mathrm{l}$ Promega reaction buffer, $0.8 \mu \mathrm{l} 25 \mathrm{mM}$ dNTP mixture, $1 \mu \mathrm{l}$ each primer, $4 \mu \mathrm{l}$ of a $25 \mathrm{mM}$ solution of $\mathrm{MgCl}_{2}, 2 \cdot 5 \mu \mathrm{l}$ of a $50 \%(\mathrm{v} / \mathrm{v})$ solution of acetamide and $70 \mu \mathrm{l}$ water. Amplified product was purified by passing it through a BioGel P-6 gel column (Bio-Rad). To prepare the amplified 16S rDNA for ligation to cloning vector pNEB193 (New England BioLabs), the product and vector were separately digested for $2 \mathrm{~h}$ at $37^{\circ} \mathrm{C}$ with AscI and PacI. The digested 16S rDNA and vector were purified by passage through a BioGel P-6 column. The PCR product was ligated into cloning vector 
pNEB193 using T4 DNA ligase (Gibco), and the ligated mixture was passed through a BioGel P-6 column. The ligated mixture was then transformed into Epicurian Coli SL1-Blue MRF' competent cells (Stratagene) by electroporation at $1.7 \mathrm{kV}$. Following electroporation, the cells were placed in SOC medium (Ausubel et al., 1994) for $1 \mathrm{~h}$ at $37^{\circ} \mathrm{C}$ and then plated onto Luria-Bertani agar containing ampicillin, IPTG and X-Gal. Plasmids were recovered from transformed colonies by inoculating selected colonies into Luria-Bertani agar containing ampicillin, incubating this overnight at $37^{\circ} \mathrm{C}$ and performing a quick boiling lysis preparation with ammonium acetate. Preparations were screened for the expected size of vector DNA plus $16 \mathrm{~S}$ rDNA by digesting the plasmids with $P a c I$ and $A s c I$ and estimating the total size by gel electrophoresis.

Automated sequencing was performed using the ABI Big Dye Primer cycle sequencing ready reaction kit (Perkin Elmer Applied Biosystems). The manufacturer's suggested PCR mixtures and temperature conditions were used. Unincorporated nucleotides, primers and dyes were removed by passing the sequencing reaction material through Centri.Sep spin columns (Princeton Separations). Sequencing was performed on an Applied Biosystems ABI 377 DNA sequencer. The $16 \mathrm{~S}$ rDNA was sequenced in both directions using M13-20 and M18-24R vector primers. The internal forward and reverse primers were as described previously (Gray \& Herwig, 1996).

The DNA sequence obtained for strain SL- $1^{\mathrm{T}}$ was compared with 16S rRNA sequences in Ribosomal Database Project II (RDP-II) using the SEQUENCE MATCH (version 2.7) analysis utility present on the RDP-II Internet web site (Maidak et al., 2001). Preliminary analysis of the sequence suggested that SL- $1^{\mathrm{T}}$ was a member of the high-G $+\mathrm{C}$ division of the Gram-positive bacteria. Phylogenetic analysis was performed using the maximum-likelihood-based program fastDNAmL, version 1.1.1a (Felsenstein, 1981; Olsen et al., 1994). Before this program could be used, some program parameters needed to be calculated. First, the category rates for each position of the $16 \mathrm{~S}$ rDNA molecule were determined by using a set of 40 randomly selected, nearly full-length and aligned $16 \mathrm{~S}$ rDNA sequences for Gram-positive, high-G + C bacteria in the RDP-II database. The program DNArates, version 1.0.0 (Maidak et al., 2001), together with fastDNAmL, was used to determine category rates. Nine category rates were calculated. To initiate this determination, a phylogenetic tree for the 40 sequences was constructed using fastDNAmL. Following the cycle, the category rates were determined using the phylogenetic tree that was found and the sequence data. These category rates were then used to construct a second tree using the same sequence data. This process was repeated again, so that the category rates that were calculated after the third cycle were then used to construct the phylogenetic tree for strain $\mathrm{SL}-1^{\mathrm{T}}$.

The 16S rDNA sequence for strain SL- $1^{\mathrm{T}}$ was aligned with a representative set of aligned 16S rRNA sequences obtained from RDP-II (Maidak et al., 2001). The sequence for strain SL- $1^{\mathrm{T}}$ and other unaligned sequences were aligned using the program SEQUENCE ALIGNER, version 1.7, on the RDP-II web site (Maidak et al., 2001). Aligned and gapped sequences were examined and manual corrections were made using the Macintosh computer program SeqPup, version 0.9 (Gilbert, 1999), and the Microsoft Windows program BioEdit, version 5.0.9 (Hall, 2001).

In addition to the category rates option, the following fastDNAmL program options were selected: the transition/ transversion ratio was set to $1 \cdot 5$; global rearrangement of the tree was permitted; and, in the input file, the sequence order was jumbled a maximum of 30 times until the best tree was found five times. Representative sequences included in the phylogenetic analyses were complete or nearly complete full-length $16 \mathrm{~S}$ rDNAs. An outgroup organism was also included in the analysis. Tree files that were generated were plotted and rearranged using the Macintosh program NJplot (Gouy, 2000).

To test the robustness of the maximum-likelihood analysis, a bootstrap analysis of the sequence data was performed using the program fastDNAmL with the bootstrap option (Felsenstein, 1981; Olsen et al., 1994). Five hundred sets of trees were generated in the bootstrap analysis and a consensus tree was generated by using CONSENSE, part of the PHYLIP version 3.6 package (Felsenstein, 1995). The program CONSENSE was run using the extended majority rule. In this option, any organism that appears in more than $50 \%$ of the trees is included. The program then considers the other sets of species in order of the frequency with which they have appeared, adding to the consensus tree any that are compatible with it until the consensus tree is fully resolved.

Strain SL- $1^{\mathrm{T}}$ was isolated from a laboratory enrichment capable of degrading TCE. Microscopic examination of SL- $1^{\mathrm{T}}$ grown on agar revealed the development of extensive mycelium (Fig. 1). Spores were observed at the ends of the cell filaments. Fully developed mycelium and formation of spores are distinct characteristics not shared by other TCEdegrading actinomycetes (Ewers et al., 1990; Kesseler et al., 1996; Saeki et al., 1999; Wackett et al., 1989) such as Mycobacterium and Rhodococcus species, which grow mainly as single cells without spore formation.

Strain SL- ${ }^{\mathrm{T}}$ grew well on agar plates and in liquid shaken cultures on both complex organic media (such as TSB) and mineral media amended with $3 \mathrm{~g}$ glucose $\mathrm{l}^{-1}$ and $30 \mathrm{mg}$ yeast extract $1^{-1}$ at room temperature. When phenol was used as a carbon and energy source, the culture developed a yellow colour, suggesting the presence of the meta-cleavage pathway of phenol degradation.

Strain SL- $1^{\mathrm{T}}$ utilized the following substrates in the Biolog GP2 MicroPlate test: glycogen, D-arabitol, D-galactose, gentiobiose, D-gluconic acid, maltose, methyl $\alpha$-D-galactoside, methyl $\alpha$-D-mannoside, D-psicose, salicin, D-sorbitol, 

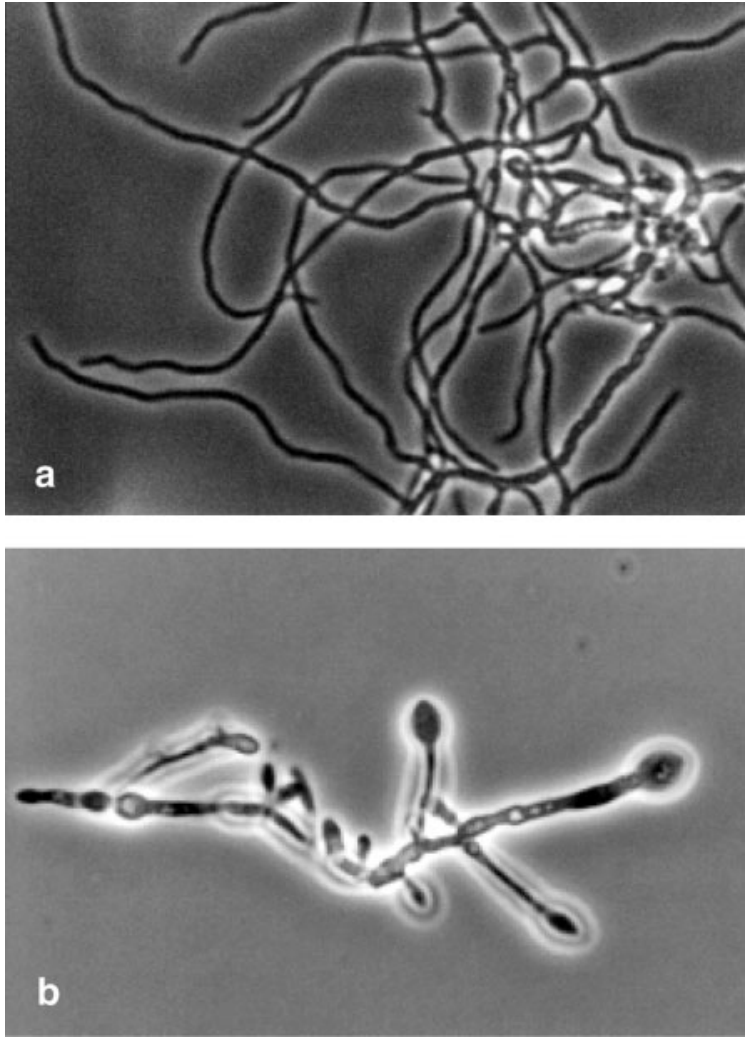

Fig. 1. Photomicrographs of cells of $P$. chloroethenivorans SL- $1^{\top}$ removed from a chemostat maintained at $25^{\circ} \mathrm{C}$ and fed with phenol $\left(14 \mathrm{mg} \mathrm{l}^{-1}\right.$ ) and mineral medium described in the text. Extensive mycelium (a) and spore formation at the ends of filaments (b) were observed.

D-trehalose, xylitol, $\gamma$-hydroxybutyric acid, $p$-hydroxyphenyl acetic acid, L-malic acid, mono-methyl succinate, Lasparagine, glycyl-L-glutamic acid, L-serine, D-cellobiose, maltotriose, D-melibiose, D-raffinose, stachyose, pyruvic acid, $N$-acetyl-D-glucosamine, D-galacturonic acid, lactulose, D-mannose, 3-methyl glucose, methyl $\alpha$-D-glucoside, palatinose, L-rhamnose, sedoheptulosan, sucrose, turanose, acetic acid, $\beta$-hydroxybutyric acid, $\alpha$-ketoglutaric acid, methyl pyruvate, propionic acid, D-alanine, L-glutamic acid, L-pyroglutamic acid, $\alpha$-D-glucose, D-mannitol, methyl $\beta$-D-galactoside and L-alanyl glycine.

The following compounds were not utilized by strain SL $-1^{\mathrm{T}}$ in the Biolog test: $\alpha$-cyclodextrin, dextrin, mannan, Tween 80 , amygdalin, L-arabinose, D-fructose, $m$-inositol, D-melezitose, D-ribose, D-tagatose, $\alpha$-hydroxybutyric acid, lactamide, L-lactic acid, D-malic acid, succinamic acid, $\mathrm{N}$-acetyl-L-glutaminic acid, 2,3-butanediol, adenosine, inosine, uridine, thymidine $5^{\prime}$-monophosphate, uridine 5 '-monophosphate, DL- $\alpha$-glycerol phosphate, $\beta$-cyclodextrin, inulin, Tween $40, N$-acetyl- $\beta$-D-mannosamine, arbutin, L-fucose, $\alpha$-D-lactose, methyl $\beta$-D-glucoside, D-xylose, $\alpha$-ketovaleric acid, D-lactic acid methyl ester, succinic acid, alaninamide, L-alanine, putrescine, glycerol, 2-deoxy adenosine, thymidine, adenosine $5^{\prime}$-monophosphate, fructose 6-phosphate, glucose 1-phosphate and glucose 6-phosphate.

Additional phenotypic tests (Table 1) used in previous taxonomic descriptions of Pseudonocardia species were performed (Huang et al., 2002; Lee et al., 2001, 2002; Reichert et al., 1998). Strain SL-1 ${ }^{\mathrm{T}}$ was capable of forming acid from most of the carbohydrates that were tested, with the exception of $\mathrm{D}(-)$-sorbitol, iso-erythritol and adonitol. Pseudonocardia hydrocarbonoxydans DSM $4321^{\mathrm{T}}$ and Pseudonocardia zijingensis AS $4.1545^{\mathrm{T}}$ also produce acid from many carbohydrates, but strain $\mathrm{SL}-1^{\mathrm{T}}$ also produced acid from $\mathrm{D}(+)$-fructose. Pseudonocardia autotrophica DSM 535 ${ }^{\mathrm{T}}$, Pseudonocardia alni IMSUNU $20049^{\mathrm{T}}$ and Pseudonocardia xinjiangensis CCTCC AA97020 ${ }^{\mathrm{T}}$ are urease-positive and $\mathrm{SL}-1^{\mathrm{T}}$ was urease-negative. Strain SL- $1^{\mathrm{T}}$ did not produce acid from adonitol, but $P$. zijingensis AS $4.1545^{\mathrm{T}}$ and P. xinjiangensis CCTCC AA97020 ${ }^{\mathrm{T}}$ do. Strain SL- $1^{\mathrm{T}}$ degraded L-tyrosine, xanthine and hypoxanthine in the presence of nutrient agar. This property is shared with Pseudonocardia sulfidoxydans DSM $44248^{\mathrm{T}}$, P. alni IMSUNN $20049^{\mathrm{T}}$ and P. zijingensis AS $4.1545^{\mathrm{T}}$. The addition of $3 \%(\mathrm{w} / \mathrm{v}) \mathrm{NaCl}$ to peptone/yeast extract agar inhibited, but did not prevent, growth of strain SL- $1^{\mathrm{T}}$. Like most other Pseudonocardia strains, strain SL- $1^{\mathrm{T}}$ did not grow at higher (4 and $5 \%, \mathrm{w} / \mathrm{v}) \mathrm{NaCl}$ concentrations. Pseudonocardia halophobica DSM $43089^{\mathrm{T}}$, P. autotrophica DSM $535^{\mathrm{T}}, P$. alni IMSUNU $20049^{\mathrm{T}}$, Pseudonocardia kongjuensis IMSNU $50583^{\mathrm{T}}$ and P. zijingensis AS $4.1545^{\mathrm{T}}$ are able to grow at the higher $\mathrm{NaCl}$ levels.

The diaminopimelic acid in whole-cell hydrolysates of strain SL- $1^{\mathrm{T}}$ was in the meso configuration, and the diagnostic sugars arabinose and galactose were detected in whole-cell hydrolysates; these features are characteristic of cell wall type IV (meso-diaminopimelic acid, arabinose and galactose). The family Pseudonocardiaceae is defined on the basis of the presence of type IV cell walls without mycolic acids (Embley et al., 1988). These data suggested that strain SL- $1^{\mathrm{T}}$ belongs to the family Pseudonocardiaceae. Strain SL- $1^{\mathrm{T}}$ possessed MK- $8\left(\mathrm{H}_{4}\right)$ as the predominant menaquinone. All species of Pseudonocardia, a genus that now also includes the members of the genera Amycolata (Warwick et al., 1994) and Actinobispora (Huang et al., 2002), contain MK- $8\left(\mathrm{H}_{4}\right)$ as the major menaquinone (Embley et al., 1988; Huang et al., 2002).

With regard to the whole-cell fatty acid composition of strain SL- $1^{\mathrm{T}}$, the fatty acid found in the largest concentration $(37 \cdot 3 \%)$ was the branched compound $16: 0$ iso (Table 2). This fatty acid was also found in the highest concentrations in P. hydrocarbonoxydans, Pseudonocardia asaccharolytica, $P$. sulfidoxydans, $P$. halophobica, $P$. autotrophica and Pseudonocardia compacta (Reichert et al., 1998). Several other fatty acids were found in strain SL- $1^{\mathrm{T}}$, but in much lower proportions. The fatty acids 16:0, 16:0 10-methyl, 17:0 iso and 17:0 anteiso were each found at concentrations of approximately $6 \%$, the 
Table 1. Physiological properties of $P$. chloroethenivorans sp. nov. SL-1 ${ }^{\top}$ and other Pseudonocardia strains

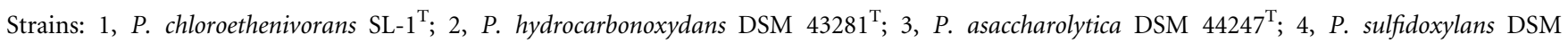
$44248^{\mathrm{T}} ; 5$, P. halophobica DSM 43089 $; 6$, P. autotrophica DSM 535 ${ }^{\mathrm{T}} ; 7$, P. compacta DSM 43592 ${ }^{\mathrm{T}} ; 8$, P. alni IMSUNU 20049 ${ }^{\mathrm{T}}$; 9 , P. kongjuensis IMSNU $50583^{\mathrm{T}}$; 10 , P. zijingensis AS $4.1545^{\mathrm{T}}$; 11, P. alaniniphila CCTCC AA97001 ${ }^{\mathrm{T}}$; 12 , P. aurantiaca CCTCC AA97002 ${ }^{\mathrm{T}}$; $13, P$. xinjiangensis CCTCC AA97020 $; 14$, P. yunnanensis AS $4.1542^{\mathrm{T}}$; 15, P. spinosispora JCM $3136^{\mathrm{T}}$. Data for reference strains were taken from Huang et al. (2002), Lee et al. (2001, 2002) and Reichert et al. (1998). +, Positive or present; W, weakly positive; -, negative or absent; NR, not reported.

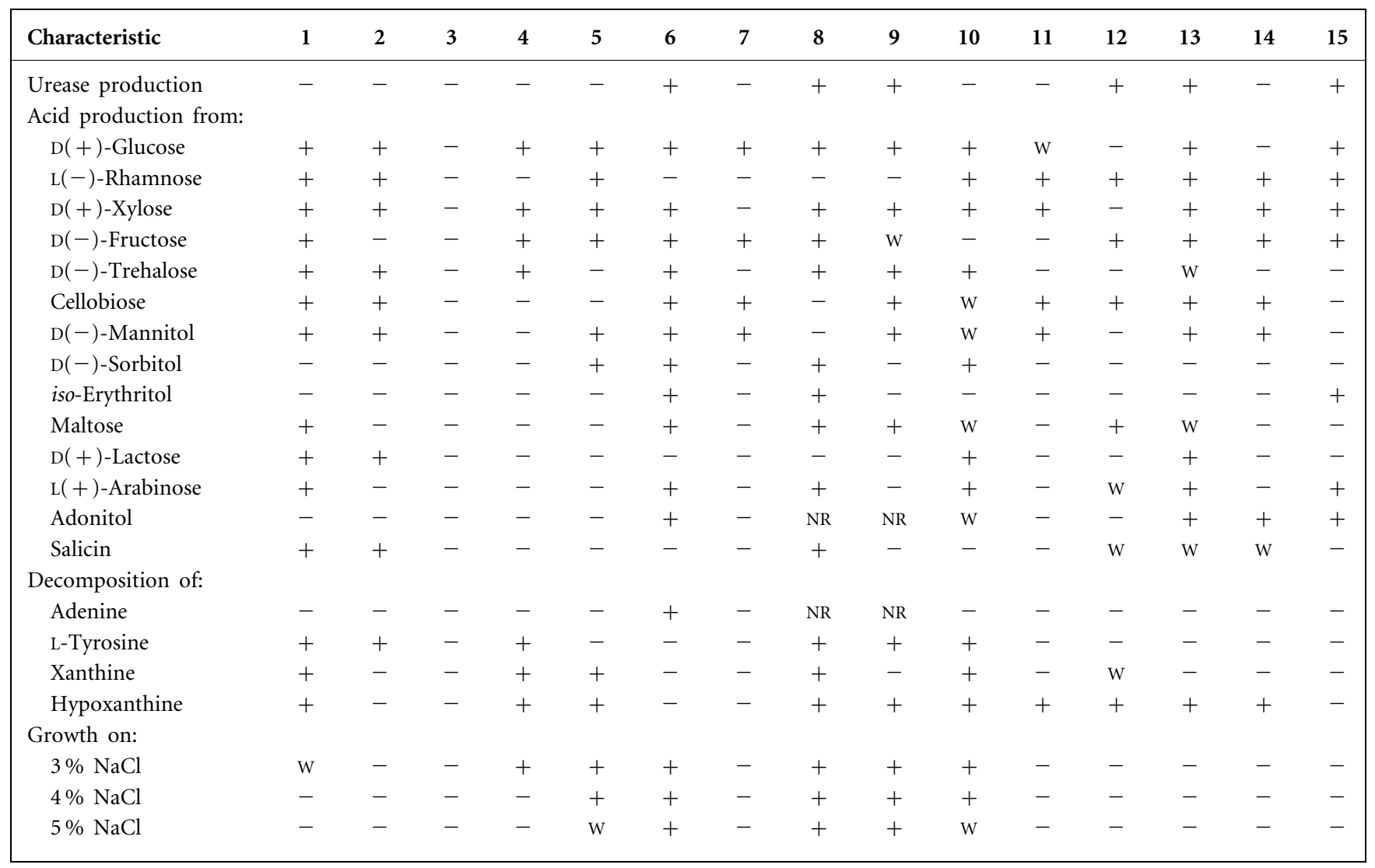

next highest concentration of fatty acid found. All other fatty acids were in lower concentrations.

Strain SL- ${ }^{\mathrm{T}}$ degraded the following chlorinated ethenes: TCE, cis-DCE and VC (Fig. 2). To avoid a decrease in the degradation rate because of possible electron donor limitation, $10 \mathrm{mg}$ phenol $1^{-1}$ was added at days 1 and 3 during the experiment. Degradation rates were the highest for cis-DCE, followed by VC and then TCE. The addition of phenol significantly enhanced the degradation rates of the chlorinated ethenes. Phenol may provide the necessary reducing power for TCE oxidation and cellular energy for repairing cell damage due to metabolite toxicity. Metabolite toxicity was previously reported for the co-metabolic degradation of chlorinated ethenes by aerobic cultures grown in the presence of phenol or methane (Sullivan et al., 1998). The ability to avoid or minimize the effects of metabolic toxicity (Bielefeldt et al., 1995) is an important consideration in the choice of organisms to add to or select for the remediation of contaminated sites. The enrichment culture from which strain SL- $1^{\mathrm{T}}$ was isolated exhibits an unusually high resistance to the toxicity of metabolites formed during co-metabolism of TCE (Lee et al., 2000). These characteristics are useful in the removal of TCE from contaminated gases and liquids, especially under conditions of high loading, e.g. in bioreactors when the contaminants are present at high concentrations. Additional research with strain SL- $1^{\mathrm{T}}$ could facilitate its application to the remediation of environmental contamination.

In recent years, strains of Pseudonocardia and other actinomycetes have been reported to degrade environmental contaminants, particularly compounds that are aromatic hydrocarbons or that contain aromatic rings. For example, Pseudonocardia strain DB1 degrades benzothiophene sulfones (Bressler et al., 1999). Seven different genera of toluene-degrading bacteria were isolated from a compost biofilter; most belonged to the genera Pseudonocardia and Rhodococcus (Juteau et al., 1999). Kohlweyer et al. (2000) recently reported the isolation of Pseudonocardia sp. strain $\mathrm{K} 1$, an organism capable of growing aerobically on tetrahydrofuran as a sole source of carbon and energy. 
Table 2. Whole-cell fatty acid composition of $P$. chloroethenivorans $S L-1^{\top}$ and of Pseudonocardia strains

Species/strains: 1, P. chloroethenivorans SL- $1^{\mathrm{T}} ; 2$, P. hydrocarbonoxydans DSM $43281^{\mathrm{T}} ; 3$, P. asaccharolytica; 4, P. sulfidoxylans; 5, P. halophobica DSM 43089 $; 6$, P. autotrophica DSM 535 ${ }^{\mathrm{T}} ; 7$, P. compacta DSM $43592^{\mathrm{T}}$. Values are percentages of total fatty acids. Data for reference strains were taken from Reichert et al. (1998).

\begin{tabular}{|c|c|c|c|c|c|c|c|}
\hline Fatty acid & 1 & 2 & 3 & 4 & 5 & 6 & 7 \\
\hline $8: 0$ & & $0 \cdot 3$ & $0 \cdot 6-1 \cdot 0$ & & & & \\
\hline $10: 0$ & & & $0 \cdot 2-0 \cdot 3$ & & & & \\
\hline $12: 0$ & & $0 \cdot 3$ & $0 \cdot 1-0 \cdot 3$ & & & & \\
\hline $13: 0$ iso & & $0 \cdot 2$ & $0 \cdot 1-0 \cdot 3$ & & & & \\
\hline $13: 0$ & & & $0 \cdot 0-0 \cdot 2$ & & & & \\
\hline $14: 0$ iso & $1 \cdot 1$ & $3 \cdot 6$ & $1 \cdot 6-2 \cdot 0$ & $1 \cdot 1-3 \cdot 4$ & $0 \cdot 8$ & $0 \cdot 3$ & $5 \cdot 7$ \\
\hline $14: 0$ & $0 \cdot 7$ & $3 \cdot 3$ & $1 \cdot 7-3 \cdot 0$ & $0 \cdot 6-3 \cdot 0$ & $0 \cdot 3$ & & $1 \cdot 1$ \\
\hline $15: 0$ iso & $4 \cdot 5$ & $10 \cdot 9$ & $8 \cdot 2-11 \cdot 4$ & $11 \cdot 2-16 \cdot 4$ & $2 \cdot 8$ & $3 \cdot 8$ & $2 \cdot 6$ \\
\hline $15: 0$ anteiso & $0 \cdot 8$ & $1 \cdot 6$ & $0 \cdot 8-1 \cdot 3$ & $0 \cdot 5-1 \cdot 7$ & $0 \cdot 9$ & & $0 \cdot 4$ \\
\hline $15: 1$ & & & & & $0 \cdot 6$ & $0 \cdot 4$ & $0 \cdot 2$ \\
\hline $15: 0$ & $1 \cdot 3$ & $2 \cdot 2$ & $1 \cdot 2-2 \cdot 6$ & $1 \cdot 3-2 \cdot 9$ & $2 \cdot 0$ & $0 \cdot 8$ & 1.9 \\
\hline $16: 1$ iso cis 9 & & $0 \cdot 7$ & $0 \cdot 5-1 \cdot 6$ & $0 \cdot 6-4 \cdot 3$ & $4 \cdot 7$ & $6 \cdot 0$ & $5 \cdot 5$ \\
\hline $16: 0$ iso & $37 \cdot 3$ & $30 \cdot 0$ & $21 \cdot 5-28 \cdot 1$ & $24 \cdot 8-32 \cdot 3$ & $52 \cdot 1$ & $52 \cdot 1$ & $51 \cdot 0$ \\
\hline $16: 1$ cis 9 & & $5 \cdot 2$ & $1 \cdot 3-6 \cdot 0$ & $1 \cdot 3-6 \cdot 0$ & $7 \cdot 5$ & $2 \cdot 4$ & $5 \cdot 1$ \\
\hline $16: 0$ & $5 \cdot 6$ & $25 \cdot 8$ & $15 \cdot 0-30 \cdot 5$ & $15 \cdot 0-30 \cdot 5$ & $6 \cdot 5$ & $4 \cdot 4$ & $11 \cdot 8$ \\
\hline 15:0 10,14-dimethyl & & $0 \cdot 5$ & $0 \cdot 1-6 \cdot 9$ & $0 \cdot 1-6 \cdot 9$ & $0 \cdot 7$ & $0 \cdot 6$ & $0 \cdot 8$ \\
\hline $17: 1$ iso cis 9 & & $1 \cdot 1$ & $0 \cdot 0-1 \cdot 0$ & $0 \cdot 0-1 \cdot 0$ & $0 \cdot 8$ & $3 \cdot 4$ & $0 \cdot 4$ \\
\hline 16:0 10-methyl & $6 \cdot 1$ & $2 \cdot 5$ & $1 \cdot 4-4 \cdot 1$ & $1 \cdot 4-4 \cdot 1$ & $4 \cdot 6$ & $2 \cdot 5$ & $2 \cdot 9$ \\
\hline $17: 0$ iso & $5 \cdot 9$ & $2 \cdot 7$ & $1 \cdot 9-9 \cdot 3$ & $1 \cdot 9-9 \cdot 3$ & $2 \cdot 4$ & $6 \cdot 9$ & $1 \cdot 3$ \\
\hline $17: 0$ anteiso & $6 \cdot 0$ & $2 \cdot 3$ & $3 \cdot 6-4 \cdot 7$ & $3 \cdot 6-4 \cdot 7$ & $6 \cdot 1$ & $2 \cdot 1$ & $1 \cdot 2$ \\
\hline $17: 1$ cis 9 & & $1 \cdot 4$ & $0 \cdot 6-4 \cdot 5$ & $0 \cdot 6-4 \cdot 5$ & $2 \cdot 4$ & $5 \cdot 2$ & $2 \cdot 4$ \\
\hline $16: 0$ iso $2-\mathrm{OH}$ & & & $0 \cdot 0-2 \cdot 8$ & $0 \cdot 0-2 \cdot 8$ & $0 \cdot 6$ & & \\
\hline $17: 0$ & $2 \cdot 0$ & $2 \cdot 7$ & $2 \cdot 5-6 \cdot 4$ & $2 \cdot 5-6 \cdot 4$ & $1 \cdot 9$ & $1 \cdot 8$ & $3 \cdot 5$ \\
\hline 16:0 10,15-dimethyl & & & $0 \cdot 0-0 \cdot 8$ & $0 \cdot 0-2 \cdot 8$ & & & \\
\hline $18: 1$ iso & $1 \cdot 5$ & & & $2 \cdot 5-6 \cdot 4$ & $0 \cdot 2$ & & \\
\hline $17: 0 \quad 10$-methyl & $3 \cdot 6$ & $0 \cdot 4$ & $0 \cdot 0-2 \cdot 5$ & $0 \cdot 0-0 \cdot 8$ & $0 \cdot 9$ & $5 \cdot 5$ & $0 \cdot 7$ \\
\hline $18: 0$ iso & $1 \cdot 5$ & $0 \cdot 2$ & $0 \cdot 0-0 \cdot 3$ & & $0 \cdot 6$ & $0 \cdot 4$ & $0 \cdot 3$ \\
\hline $18: 1$ cis 9 & $0 \cdot 6$ & $1 \cdot 2$ & & $0 \cdot 0-2 \cdot 5$ & & & $0 \cdot 1$ \\
\hline $18: 0$ & $0 \cdot 9$ & $0 \cdot 8$ & $0 \cdot 0-1 \cdot 1$ & $0 \cdot 0-0 \cdot 3$ & & $0 \cdot 3$ & $0 \cdot 5$ \\
\hline
\end{tabular}

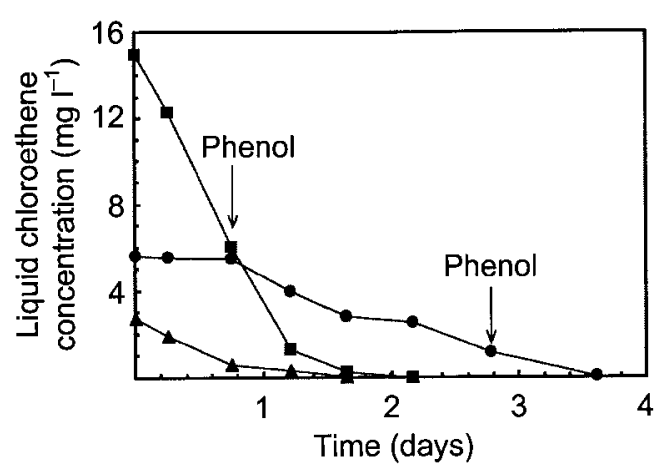

Fig. 2. Degradation of individual chloroethenes [TCE (O), cisDCE ( $\boldsymbol{\square})$ and VC $(\boldsymbol{\Delta})$ ] by $P$. chloroethenivorans SL-1 ${ }^{\top}$. At days 1 and $3,10 \mathrm{mg}$ phenol $\mathrm{I}^{-1}$ was added.
The nearly complete $16 \mathrm{~S}$ rDNA sequence for strain SL- ${ }^{\mathrm{T}}$ consisted of 1444 nucleotides. This sequence was compared with prokaryote sequences present in RDP-II (Maidak et al., 2001) and GenBank (Altschul et al., 1997). A preliminary comparison of the $16 \mathrm{~S}$ rDNA with sequences present in the databases suggested that $\mathrm{SL}-1^{\mathrm{T}}$ was a species of Pseudonocardia. Therefore, recognized type strains of Pseudonocardia and representative Gram-positive bacteria were included in the dataset for the phylogenetic analysis. Strain SL- $1^{\mathrm{T}}$ showed the greatest similarity, in terms of $16 \mathrm{~S}$ rDNA sequence, to the following organisms with nearly complete sequences (numbers in parentheses indicate the percentage similarity and the fraction of bases from strain SL- $1^{\mathrm{T}}$ that were compared to the $16 \mathrm{~S}$ rDNA sequence from the databases): Pseudonocardia yunnanensis (96\%, 1399/1445), P. hydrocarbonoxydans (96\%, 1396/1444), P. sulfidoxydans $(96 \%, 1406 / 1456)$, P. halophobica (96\%, 1390/1445), Pseudonocardia petroleophila (96\%, 1391/1448), 


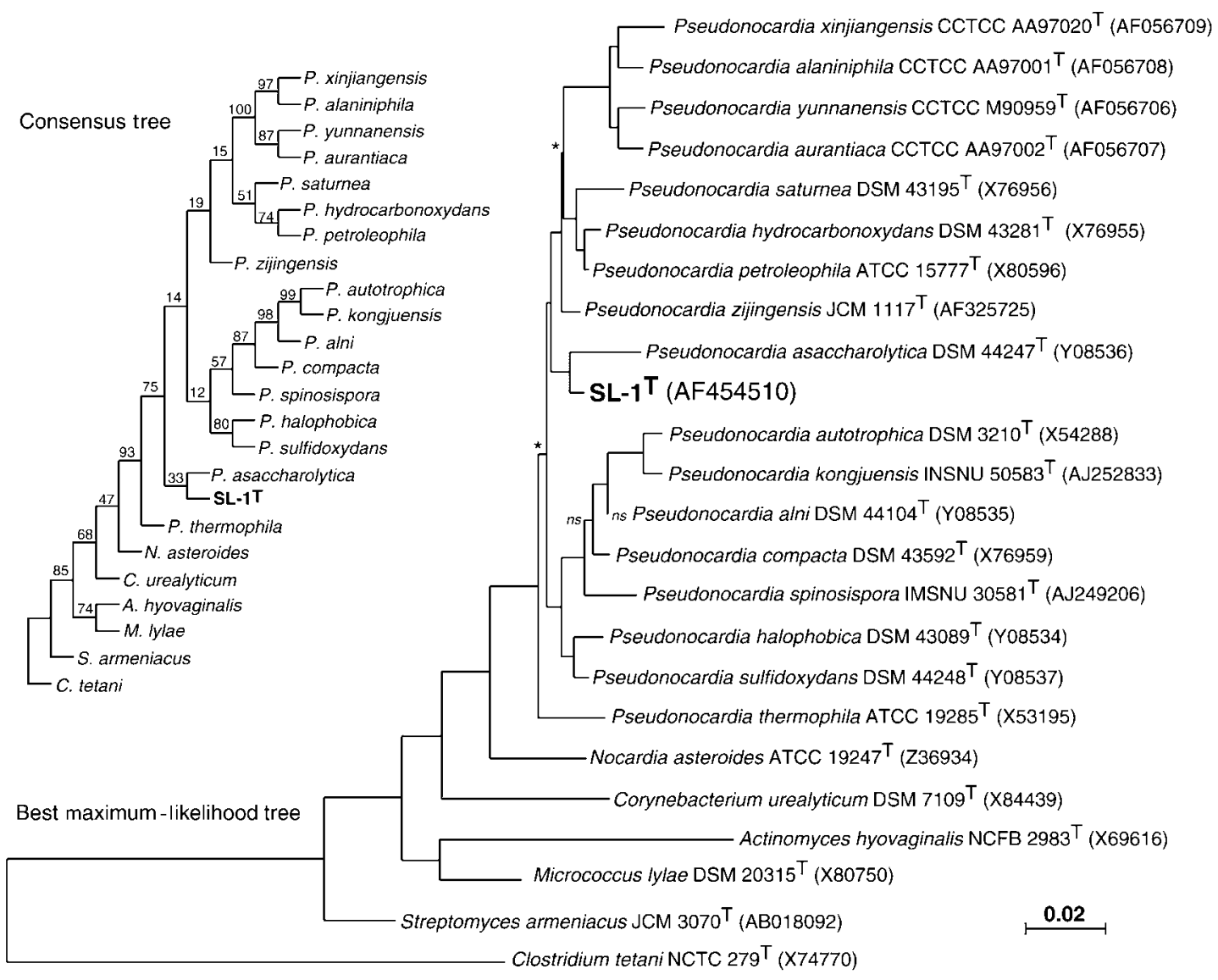

Fig. 3. Best maximum-likelihood phylogenetic tree and consensus phylogenetic tree for $P$. chloroethenivorans $S L-1^{\top}$, Pseudonocardia species and other representative Gram-positive bacteria based on 16S rDNA sequences. In the maximumlikelihood tree, the letters ' $n s^{\prime}$ by species names and nodes indicate branch lengths that are not significant; asterisks $\left({ }^{*}\right)$ indicate branch lengths that are significantly positive at the $P<0.05$ level. All of the remaining branch lengths are significantly positive at $P<0 \cdot 01$. Bar, 2 nucleotide changes per 100 bases. The consensus phylogenetic tree was produced following the bootstrap sampling of 500 datasets. Numbers above horizontal branches in the tree represent percentages of bootstrap trees that conform to the branching order presented in the consensus tree. The consensus tree only provides the branching order, not the evolutionary distances between nodes.

P. zijingensis $(97 \%, 1233 / 1263)$ and $P$. asaccharolytica (95\%, 1384/1450) (Altschul et al., 1997). No type strains of Pseudonocardia species showed 16S rDNA similarity greater than $97 \%$.

A phylogenetic tree (Fig. 3) was constructed using a maximum-likelihood program. The outgroup used for the tree was Clostridium tetani NCTC $279^{\mathrm{T}}$. The $\ln$ (likelihood) value for the tree was $-8013 \cdot 50628$. All but four branch lengths are significantly positive $(P<0 \cdot 1)$. Two branches were significantly positive only at $P<0 \cdot 5$, and two branches did not have a significant length. The best tree found placed strain SL-1 ${ }^{\mathrm{T}}$ in a clade of organisms composed of species of the genus Pseudonocardia. As shown in Fig. 3, Pseudonocardia species, including species that were formerly members of the genus Actinobispora (Huang et al., 2002), are phylogenetically very closely related to each other. To examine the robustness of the maximum-likelihood analysis, the data were bootstrapped 500 times; the resulting consensus tree is also presented in Fig. 3. Results of the consensus analysis showed the association of strain SL- $1^{\mathrm{T}}$ with the clade consisting of species of Pseudonocardia. Unfortunately, the phylogenetic information provided by the $16 \mathrm{~S}$ rDNA did not place strain SL- $1^{\mathrm{T}}$ consistently during the bootstrap analysis within a well-defined smaller clade of organisms within the phylogenetic tree. As in the best maximum-likelihood tree (Fig. 3 ), in the bootstrap analysis SL- ${ }^{\mathrm{T}}$ was phylogenetically associated with $P$. asaccharolytica DSM $44247^{\mathrm{T}}$, but this association was found in only $33 \%$ of the bootstrap trees. On the other hand, strains that were formerly described as members of the genus Actinobispora (Huang et al., 2002), i.e. Pseudonocardia aurantiaca CCTCC AA97002 ${ }^{\mathrm{T}}$, Pseudonocardia alaniniphila CCTCC AA97001 ${ }^{\mathrm{T}}$, P. yunnanensis CCTCC M90959 $9^{\mathrm{T}}$ and P. xinjiangensis CCTCC AA97020 ${ }^{\mathrm{T}}$, were members of the same clade in $100 \%$ of the bootstrap analyses. The reason 
for the poor resolution of strain SL- ${ }^{\mathrm{T}}$ was the somewhat ambiguous nature of the $16 \mathrm{~S}$ rDNA of strain SL- $1^{\mathrm{T}}$, as suggested by the results of the program CHIMERA_CHECK. This program was developed primarily to look for the presence of chimeras in 16S rDNA clones (Maidak et al., 2001). The first 790 bases of strain SL- $1^{T}$ 16S rRNA showed greater similarity to $16 \mathrm{~S}$ rDNA from $P$. yunnanensis CCTCC $\mathrm{M} 90959^{\mathrm{T}}$, while the $3^{\prime}$ end of the molecule showed greater similarity to $P$. sulfidoxydans DSM $44248^{\mathrm{T}}$. Thus, a bootstrap analysis of the phylogenetic data led to poor resolution of the placement of strain SL- $1^{\mathrm{T}}$ within the closely related clade of Pseudonocardia species. Despite the close phylogenetic affinity between strain SL- $1^{\mathrm{T}}$ and $P$. asaccharolytica DSM $44247^{\mathrm{T}}$, they could be easily differentiated from each other by means of many phenotypic characteristics (Table 1).

On the basis of the 16S rRNA gene sequence, physiological properties (including the ability to degrade chloroethenes and phenol) and chemotaxonomic characteristics, we propose that strain $\mathrm{SL}-1^{\mathrm{T}}$ be considered a novel species, with the name Pseudonocardia chloroethenivorans sp. nov.

\section{Description of Pseudonocardia chloroethenivorans sp. nov.}

Pseudonocardia chloroethenivorans sp. nov. (chlor.o.e.the. ni.vor' ans. N.L. n. chloroethenum chloroethene; L. part. adj. vorans devouring; N.L. part. fem. adj. chloroethenivorans chloroethene-devouring).

Cells are Gram-positive and aerobic. Vegetative and aerial hyphae are branched but not fragmented. Spores are borne at the ends of hyphae and are not motile. Vegetative mycelia are white. Diffusible pigments not observed. Cells use a variety of organic compounds. Acid is produced from $\mathrm{D}(+)$-glucose, $\mathrm{L}(-)$-rhamnose, $\mathrm{D}(+)$-xylose, $\mathrm{D}(-)$ trehalose, cellobiose, $\mathrm{D}(-)$-mannitol, maltose, $\mathrm{D}(+)$-lactose, $\mathrm{L}(+)$-arabinose and salicin. L-Tyrosine, xanthine and hypoxanthine are degraded. Adenine is not degraded. Urea is not degraded. Growth does not occur in the presence of 4 or $5 \%(\mathrm{w} / \mathrm{v}) \mathrm{NaCl}$. Capable of growing on phenol as a source of carbon and energy. TCE, cis-DCE and VC are degraded. Cell wall contains meso-diaminopimelic acid as the diamino acid. Whole-cell hydrolysate contains galactose and arabinose. Lacks mycolic acid. Major menaquinone is MK- $8\left(\mathrm{H}_{4}\right)$. The fatty acid found in the largest amounts in whole-cell preparations is 16:0 iso.

The type strain, SL $-1^{\mathrm{T}}\left(=\right.$ ATCC BAA $\left.-742^{\mathrm{T}}=\mathrm{DSM} 44698^{\mathrm{T}}\right)$, was isolated from an aerobic laboratory enrichment in the Department of Civil and Environmental Engineering, University of Washington, Seattle, WA, USA.

\section{Acknowledgements}

We thank Jennifer L. McLarnan for technical assistance with the cloning and sequencing of the $16 \mathrm{~S}$ rDNA of strain SL- $1^{\mathrm{T}}$. Benjamin A. Paulson performed the fatty acid analysis. Professor Dr Hans G.
Trüper provided assistance with the naming of the species. We appreciate the comments of the anonymous referees and the editors of the Journal. The research was supported by grants from the National Institute of Environmental Health Sciences (ES-04696) and the Environmental Protection Agency (G71A0709).

\section{References}

Altschul, S. F., Madden, T. L., Schäffer, A. A., Zhang, J., Zhang, Z., Miller, W. \& Lipman, D. J. (1997). Gapped BLAST and PSI-BLAST: a new generation of protein database search programs. Nucleic Acids Res 25, 3389-3402.

Ausubel, F. M., Brent, R., Kingston, R. E., Moore, D. D., Seidman, J. G., Smith, J. A. \& Struhl, K. (editors) (1994). Current Protocols in Molecular Biology. New York: Wiley.

Bielefeldt, A. R., Stensel, H. D. \& Strand, S. E. (1995). Cometabolic degradation of TCE and DCE without intermediate toxicity. J Environ Eng ASCE 121, 791-797.

Bressler, D. C., Leskiw, B. K. \& Fedorak, P. M. (1999). Biodegradation of benzothiophene sulfones by a filamentous bacterium. Can J Microbiol 45, 360-368.

Coutts, R. T., Hargesheimer, E. E. \& Pasutto, F. M. (1979). Gas chromatographic analysis of trace phenols by direct acetylation in aqueous solution. J Chromatogr 12, 291-299.

Embley, T. M., Smida, J. \& Stackebrandt, E. (1988). Reverse transcriptase sequencing of $16 \mathrm{~S}$ ribosomal RNA from Faenia rectivirgula, Pseudonocardia thermophila and Saccharopolyspora hirsuta, three wall type IV actinomycetes which lack mycolic acids. J Gen Microbiol 134, 961-966.

Ensley, B. D. (1991). Biochemical diversity of trichloroethylene metabolism. Annu Rev Microbiol 45, 283-299.

Evtushenko, L. I., Akimov, V. N., Dobritsa, S. V. \& Taptykova, S. D. (1989). A new species of actinomycete, Amycolata alni. Int J Syst Bacteriol 39, 72-77.

Ewers, J., Freier-Schröder, D. \& Knackmuss, H. J. (1990). Selection of trichloroethene (TCE) degrading bacteria that resist inactivation by TCE. Arch Microbiol 154, 410-413.

Felsenstein, J. (1981). Evolutionary trees from DNA sequences: a maximum likelihood approach. J Mol Evol 17, 368-376.

Felsenstein, J. (1995). PHYLIP (Phylogeny Inference Package) version 3.573. University of Washington, Seattle, USA.

Fetzner, S. (1998). Bacterial dehalogenation. Appl Microbiol Biotechnol 50, 633-657.

Gerritse, J., Renard, V., Visser, J. \& Gottschal, J. C. (1995). Complete degradation of tetrachloroethene by combining anaerobic dechlorinating and aerobic methanotrophic enrichment cultures. Appl Microbiol Biotechnol 43, 920-928.

Gilbert, D. G. (1999). SeqPup, a biological sequence editor and analysis program written in java. Available at http://iubio.bio. indiana.edu

Gordon, R. E., Barnett, D. A., Handerhan, J. E. \& Pang, C. H.-N. (1974). Nocardia coeliaca, Nocardia autotrophica, and the nocardin strain. Int J Syst Bacteriol 24, 54-63.

Gouy, M. (2000). NJplot. Laboratoire de Biométrie et Biologie Evolutive, Université Lyon. http://pbil.univ-lyon1.fr/software/njplot. html

Gray, J. P. \& Herwig, R. P. (1996). Phylogenetic analysis of the bacterial communities in marine sediments. Appl Environ Microbiol 62, 4049-4059.

Hall, T. (2001). BioEdit. Department of Microbiology, North Carolina State University. 
Huang, Y., Wang, L., Lu, Z., Hong, L., Liu, Z., Tan, G. Y. A. \& Goodfellow, M. (2002). Proposal to combine the genera Actinobispora and Pseudonocardia in an emended genus Pseudonocardia, and description of Pseudonocardia zijingensis sp. nov. Int J Syst Evol Microbiol 52, 977-982.

Juteau, P., Larocque, R., Rho, D. \& LeDuy, A. (1999). Analysis of the relative abundance of different types of bacteria capable of toluene degradation in a compost biofilter. Appl Microbiol Biotechnol 52, 863-868.

Kesseler, M., Dabbs, E. R., Averhoff, B. \& Gottschalk, G. (1996). Studies on the isopropylbenzene 2,3-dioxygenase and the 3-isopropylcatechol 2,3-dioxygenase genes encoded by the linear plasmid of Rhodococcus erythropolis BD2. Microbiology 142, 3241-3251.

Kohlweyer, U., Thiemer, B., Schrader, T. \& Andreesen, J. R. (2000). Tetrahydrofuran degradation by a newly isolated culture of Pseudonocardia sp. strain K1. FEMS Microbiol Lett 186, 301-306.

Komagata, K. \& Suzuki, K.-I. (1987). Lipids and cell-wall analysis in bacterial systematics. Methods Microbiol 19, 161-203.

Lee, S.-B., Strand, S. E. \& Stensel, H. D. (2000). Sustained degradation of trichloroethylene in a suspended growth gas treatment reactor by an actinomycetes enrichment. Environ Sci Technol 34, 3261-3268.

Lee, S. D., Kim, E. S., Min, K.-L., Lee, W. Y., Kang, S.-O. \& Hah, Y. C. (2001). Pseudonocardia kongjuensis sp. nov., isolated from a gold mine cave. Int J Syst Evol Microbiol 51, 1505-1510.

Lee, S. D., Kim, E. S., Kang, S.-O. \& Hah, Y. C. (2002). Pseudonocardia spinosispora sp. nov., isolated from Korean soil. Int J Syst Evol Microbiol 52, 1603-1608.

Maidak, B. L., Cole, J. R., Lilburn, T. G. \& 7 other authors (2001). The RDP-II (Ribosomal Database Project). Nucleic Acids Res 29, 173-174.

MIDI (1993). Microbial Identification System Operational Manual. Newark, NJ: MIDI.

Nelson, M. J., Montgomery, S. O., Mahaffey, W. R. \& Pritchard, P. H. (1987). Biodegradation of trichloroethylene and involvement of an aromatic biodegradative pathway. Appl Environ Microbiol 53, 949-954.
Nelson, M. J., Montgomery, S. O. \& Pritchard, P. H. (1988). Trichloroethylene metabolism by microorganisms that degrade aromatic compounds. Appl Environ Microbiol 54, 604-606.

Olsen, G. J., Matsuda, H., Hagström, R. \& Overbeek, R. (1994). fastDNAmL: a tool for construction of phylogenetic trees of DNA sequences using maximum likelihood. Comput Appl Biosci 10, 41-48.

Reichert, K., Lipski, A., Pradella, S., Stackebrandt, E. \& Altendorf, K. (1998). Pseudonocardia asaccharolytica sp. nov. and Pseudonocardia sulfidoxydans sp. nov., two new dimethyl disulfide-degrading actinomycetes and emended description of the genus Pseudonocardia. Int J Syst Bacteriol 48, 441-449.

Saddler, G. S., Tavecchia, P., Lociuro, S., Zanol, M., Colombo, L. \& Selva, E. (1991). Analysis of madurose and other actinomycete whole cell sugars by gas chromatography. J Microbiol Methods 14, 185-191.

Saeki, H., Akira, M., Furuhashi, K., Averhoff, B. \& Gottschalk, G. (1999). Degradation of trichloroethene by a linear-plasmid-encoded alkene monooxygenase in Rhodococcus corallinus (Nocardia corallina) B-276. Microbiology 145, 1721-1730.

Semprini, L. (1995). In situ bioremediation of chlorinated solvents. Environ Health Perspect 103 (Suppl. 5), 101-105.

Sullivan, J. P., Dickinson, D. \& Chase, H. A. (1998). Methanotrophs, Methylosinus trichosporium OB3b, sMMO, and their application to bioremediation. Crit Rev Microbiol 24, 335-373.

US Environmental Protection Agency (1991). Survey of Materialhandling Technologies Used at Hazardous Waste Sites. National Technical Information Service order number PB91-921283, report number EPA/540/2-91/010. Washington, DC: US Government Printing Office.

Wackett, L. P., Brusseau, G. A., Householder, S. R. \& Hanson, R. S. (1989). Survey of microbial oxygenases: trichloroethylene degradation by propane-oxidizing bacteria. Appl Environ Microbiol 55, 2960-2964.

Warwick, S., Bowen, T., McVeigh, H. \& Embley, T. M. (1994). A phylogenetic analysis of the family Pseudonocardiaceae and the genera Actinokineospora and Saccharothrix with 16S rRNA sequences and a proposal to combine the genera Amycolata and Pseudonocardia in an emended genus Pseudonocardia. Int J Syst Bacteriol 44, 293-299. 